\title{
Application of Fracture Mechanics to Cracking Problems in Soils
}

\author{
G. Juárez-Luna ${ }^{1, *}$ and G. Ayala ${ }^{2}$
}

\author{
${ }^{I}$ Materials Department, Universidad Autónoma Metropolitana, San Pablo No. 180, Col. Reynosa Tamaulipas, \\ Azcapotzalco, 02200, Mexico City, Mexico; ${ }^{2}$ Institute of Engineering, Universidad Nacional Autónoma de México, \\ Ciudad Universitaria, Coyoacán, 04510, Apdo, 70-642, Mexico City, Mexico
}

\begin{abstract}
This paper analyzes the problem of fracture in soils using the linear elastic fracture mechanics theory. Six cases of practical interest are investigated where the soil is subjected to different critical conditions that may produce cracks. To model the phenomenon of crack propagation, a two-dimensional fracture mechanics finite element program is used. In all cases, the properties of clays in the Valley of Mexico was used. The self-weight of the soil is considered as the main cause of geostatic stresses in the medium. Based on results from previous studies, the value of the critical stress intensity factor is calculated and validated. It is assumed that, only mode I fracture occurs. The crack depths obtained with the numerical models are congruent with the field data of existing geotechnical studies in the Valley of Mexico.
\end{abstract}

Keywords: Fracture mechanics, crack propagation, stress intensity factor, cracking in soils.

\section{INTRODUCTION}

It is well known that cracking in soils is a phenomenon frequently present in clayed soils such as those found in the Valley of Mexico (Mexico City), where the occurrence of this phenomenon has increased dramatically in the last decades. Cracking in soils has been studied for almost 50 years. Although this problem has been mainly attributed to two causes subsidences and filtration forces, there still exist some cases where causes of cracking are not well known.

Field evidence has shown that the cracking in soils can be attributed to soil subsidence in deposits on topographic irregularities [1]. These irregularities cause non uniform distribution of subsidences and, consequently, of stresses which may lead to a fracture process in the soil layer. These situations have been rarely investigated as variations in groundwater have been considered until now as the most important cause of cracking.

Regarding the effect of change in groundwater conditions, [2] put forward the basic idea that evaporation and subsequent water infiltration are the main causes of cracking in soils; he stated that intense superficial evaporation produced by solar radiation causes tensile stress in the water contained in the upper part of the stratum. Because these conditions cause the soil to dry with time, a process of consolidation is developed and, consequently, tensile stresses in the water increase and compressive stresses in the soil structure are generated. When rain is present, a layer of water is formed on the surface of the stratum, destroying the soil meniscus formed in the interstitial spaces of this surface and causing the transference of the tensile stresses in the water to the soil and the possible growth of existing cracks.

An observation of cracks in the Eloy Picacho zone in Arizona was reported by [3], concluding that the relationship

*Address correspondence to this author at the Materials Department, Universidad Autónoma Metropolitana, San Pablo No. 180, Col. Reynosa Tamaulipas, Azcapotzalco, 02200, Mexico City; Tel: (+5255) 53189085; Fax: (+5255) 53189085; E-mail: gjl@correo.azc.uam.mx between the subsidence of the valley and cracking was not evident. With reference to the same cracks, [4] found a relationship between the occurrence of cracking and the drop in groundwater level. The existence of cracks in the states of Arizona, California, Idaho, Texas and Nevada is described by [5], stating that these cracks occurred suddenly and frequently during strong rains. Seven favorable conditions for the occurrence of cracking in soils when the groundwater level is lowered were described in the work of [1].

The first authors to suggest that Linear Elastic Fracture Mechanics, (LEFM), could be used to study the progressive failure process of slopes made of fissured clays were [6] and [7]. The principles of the LEFM theory were used by [8] to interpret the failure mechanism of fissured kaolinite clay samples subjected to compression and direct shear stress conditions.

More recently, the behavior of an initial crack exposed to the pressure of water infiltrated when it rains was investigated by [9]. In their study, the parameter governing the fracture process was $K$, calculated with an indirect procedure. A formulation in [10], based on the theory of elasticity, considered that the filtration forces are the main cause of tensions in the soil structure, and these tensions may cause the cracking.

The purpose of this work is to investigate the phenomenon of cracking in soils using the two-dimensional LEFM theory. This paper addresses the occurrence of cracks in six cases of practical interest, where the causes of cracking are the subsidences due to the irregularity of bearing layers and filtration forces. In the solution of this problem, the program FRANC2D [11], based on the FEM, was used.

\section{DISCRETE MODELING OF TWO-DIMENSIONAL CRACK PROPAGATION}

The discrete modeling of crack propagation problems is an evolutive process which involves four stages in each 
simulation step. Fig. (1) shows the stages to be performed during the modeling of the propagation of a crack.

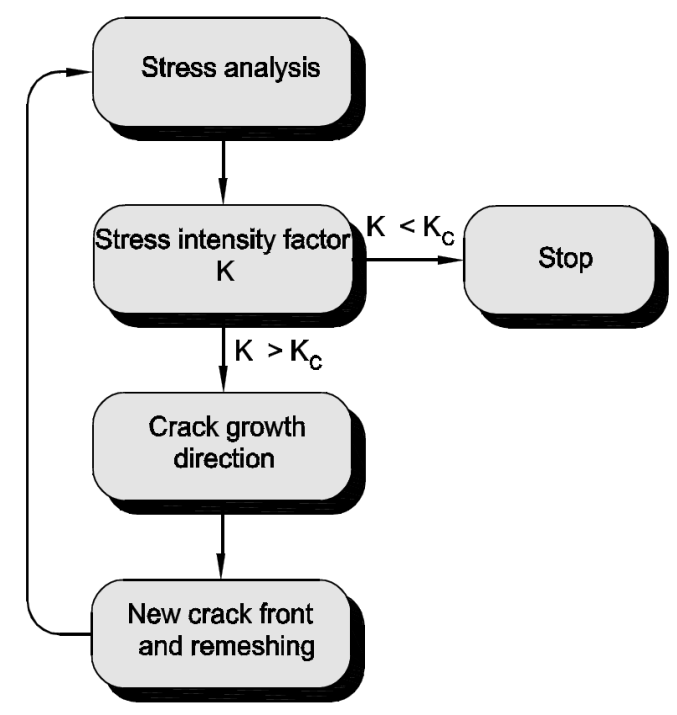

Fig. (1). Discrete modeling of crack propagation.

The first stage in the simulation of the propagation of a crack is a stress analysis. The purpose of this step is to compute the stresses, strains, and displacements due to imposed boundary conditions (loads and restraints). This analysis is performed through numerical methods; mainly, by the Finite Element Method and the Boundary Integral Equation Method (BIEM). To model the singular stress field at the tip of the crack, the FEM uses quarter-point finite elements in the crack region whereas the BIEM uses a hyper-singular formulation for one of the edges of the crack. In both methods, the accuracy of the results depends on the density of the mesh and on the type of element used.

The second stage of the process involves the calculation of the $K$ which is one of the parameters that govern the fracture process and most commonly used for the simulation of crack-growth. Other parameters are $G, J$, and $C T O D$. It is with any of these parameters that the prediction of crack growth may be carried out. In the present study, $K_{I}$ is used.

The third stage in the crack-growth simulation is the calculation of the direction of growth in the crack-tip region using one of the existing theories for determining the angle of crack propagation. Three of the most often used are the maximum principal stress theory, the maximum energy release rate theory, and the minimum strain energy density theory. In the present study, the maximum principal stress theory is used.

The fourth stage in the crack-growth simulation is the determination of the crack and the remeshing of the domain considering an approach used to model the propagation of a crack within an FEM program, namely delete-and-fill method introduced by [12] and illustrated in Fig. (2), where the strategy is: a) delete a group of elements in a region around the current crack tip, b) extend the crack into this region, c) place well-formed quarter-point finite elements around the new crack tip and create a transition mesh that fills the area left between the crack-tip elements and the original untouched mesh.

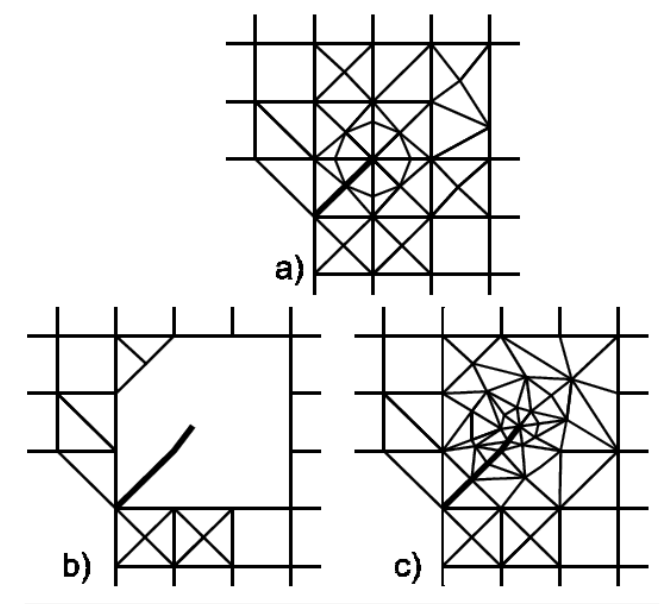

Fig. (2). Delete-and-fill remeshing method for crack propagation simulation.

\section{DETERMINATION OF $K_{I C}$}

Due to the difficulty involved in the determination of the experimental value of $K_{I C}$ of the clays of the Valley of Mexico, in the present study the value of $K_{I C}=12.7 \mathrm{kPa} \sqrt{\mathrm{m}}$, reported in [9], was taken. The properties of the drained clays in the Valley of Mexico being $\mathrm{E}=6,717.55 \mathrm{kPa}, v=0.3$ and $\sigma_{\mathrm{YS}}=98.1 \mathrm{kPa}$ were used.

\section{INVESTIGATED CASES}

In this section, six cases of practical interest are investigated. In the first two, two of the seven favorable situations of cracking in soils as described by [1], were modeled: a clay layer deposited on a topographical irregularity and a clay layer deposited on a rock slope. The third case corresponded to a clay layer deposited on a step irregularity [13]. In the fourth and fifth cases, cracking due to water pressure in a soil layer, and cracking due to evaporation and subsequent infiltration were correspondingly investigated. Finally, in the last case, cracking due to a puddle formed on the ground surface was modeled.

To locate the potential zones of cracking in the first three plane strain cases, stress analyses were carried out using as loading, the self-weight of the clay. The domains were discretized using a mesh of 8-noded quadrilateral and 6-noded triangular finite elements. The horizontal displacements of the vertical sides and both horizontal and vertical displacements of the bottom sides next to the rock base were considered fixed.

Once the preliminary analyses were carried out, initial cracks were introduced in the models at the location of maximum tensile stress in the soil layer and the conditions for crack-growth were then verified. When crack propagation was due, the length of the crack was increased and the analysis repeated until no propagation was possible.

The FEM models were analyzed using the program FRANC2D. The parameter governing the fracture process is the critical stress intensity factor, considered as $K_{I C}=12.7$ $\mathrm{kPa} \sqrt{\mathrm{m}}$. The crack-growth process is active when the value of $K_{I}$ is greater than or equal to the value of $K_{I C}$. The considered size of the crack-extension increment is $0.25 \mathrm{~m}$ for the 
first three cases and $0.10 \mathrm{~m}$ for the last two. The maximum principal stress theory was used to calculate the crack growth direction.

\section{Case 1: Clay Layer Deposited on a Topographical Irregularity}

To confirm the statement by [1], that the cracking phenomenon in soils is favorable in a soil layer deposited on a cylindrical rock base, this example, illustrated in Fig. (3), corresponds to a $30 \mathrm{~m}$ deep clay layer and a rock irregularity of radius, $\mathrm{r}=10 \mathrm{~m}$.

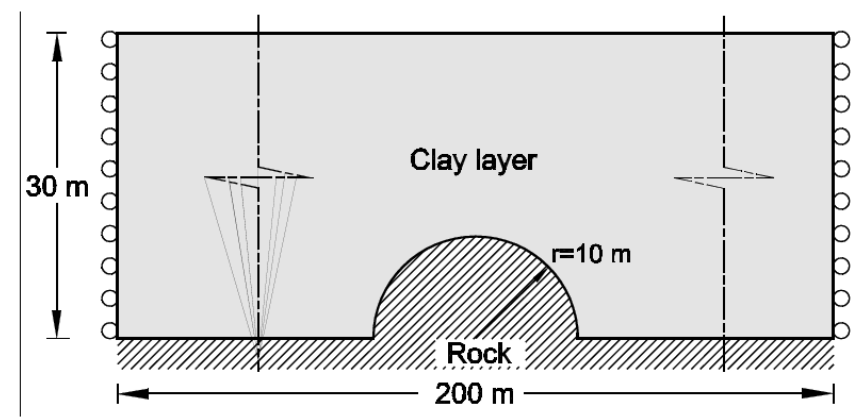

Fig. (3). Geometry of the model of a clay layer deposited on a topographical irregularity.

The horizontal stress distribution due to self-weight is shown in Fig. (4). A tensile stressed region with potential to the appearance of cracks is observed at the central upper part of the layer. This region reaches a depth of $6.8 \mathrm{~m}$.

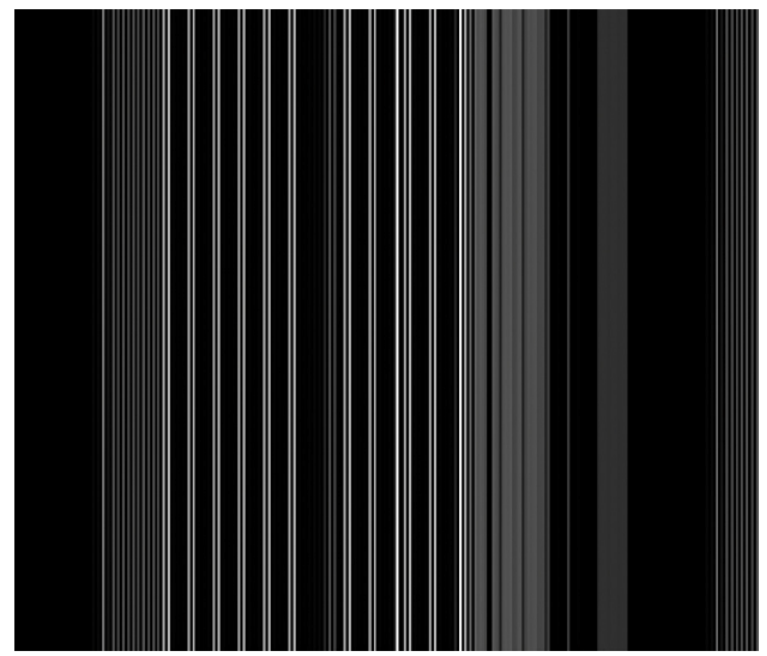

Fig. (4). Horizontal stress distribution in a clay layer deposited on a topographical irregularity.

To investigate the fracture process, an initial crack is inserted in the region with the highest tensile stresses (Fig. 5). Two analyses were carried out with initial crack lengths of 1 and $2 \mathrm{~m}$ respectively.

The normalized stress intensity factors calculated during the incremental analysis of growth of the cracks are shown in Fig. (6). According to this, the crack reaches a depth of 8.15 $\mathrm{m}$ in both analyses and an aperture $\mathrm{b}=19.3 \mathrm{~cm}$, in the upper part (Fig. 7).

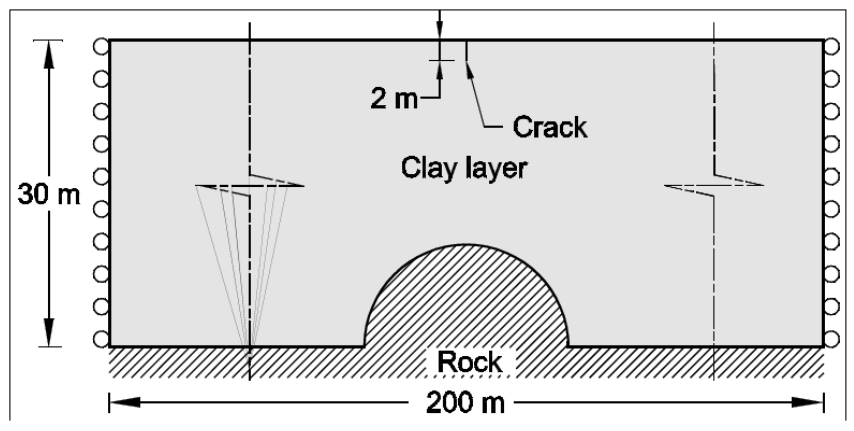

Fig. (5). Cracked clay layer deposited on a topographical irregularity.

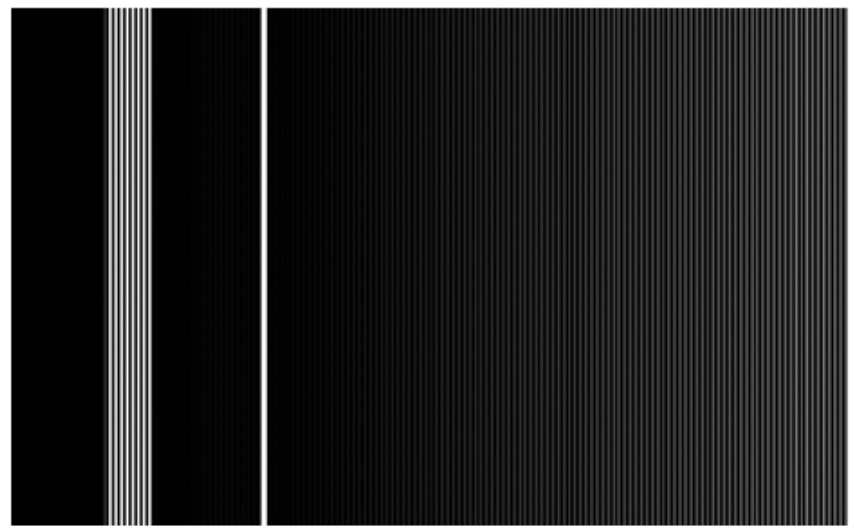

Fig. (6). Variation of $K_{I} / K_{I C}$ vs. crack-depth corresponding to a cracked clay layer deposited on a topographical irregularity.

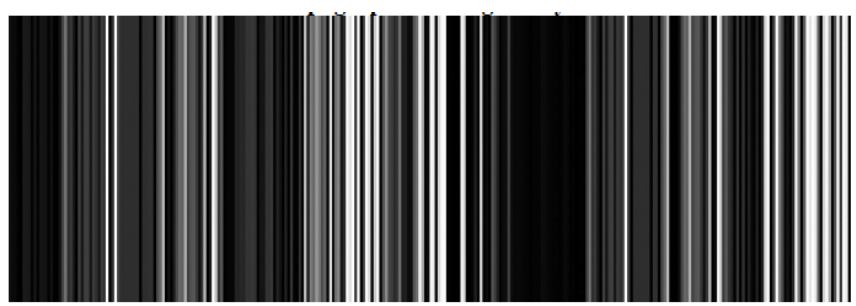

Fig. (7). Simulation of crack growth with hFRANC2D.Cracked clay layer deposited on a topographical irregularity.

\section{Case 2: Clay Layer Deposited on a Rock Slope}

Other statement by [1] is that the occurrence of cracks is also favorable in a soil layer deposited on a rock slope. Thus, this example studies the $30 \mathrm{~m}$ deep clay layer shown in Fig. (8).

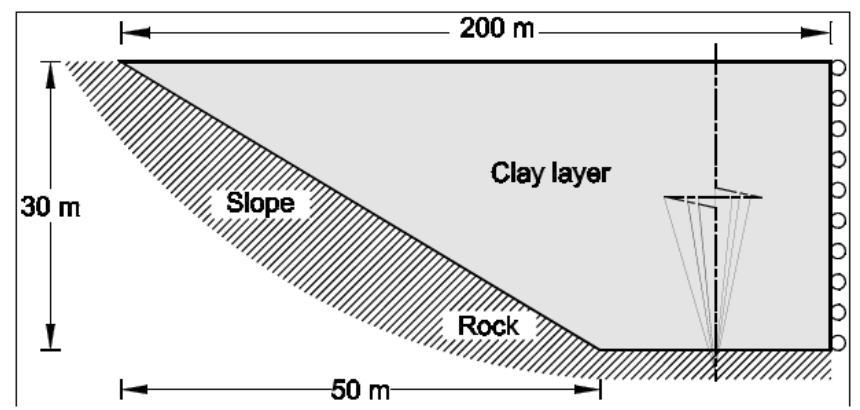

Fig. (8). Geometry of a clay layer deposited on a rock slope. 
The distribution of horizontal stresses obtained from the geostatic analysis of this case is shown in Fig. (9). A tensile stress region with potential to the occurrence of cracks is observed at the upper left hand corner of the layer. This region reaches a depth of $6.7 \mathrm{~m}$ and the maximum tensile stress is located $14 \mathrm{~m}$ to the left of the upper tip of the dipping layer. At this location, an initial crack $1 \mathrm{~m}$ long is introduced (Fig. 10).

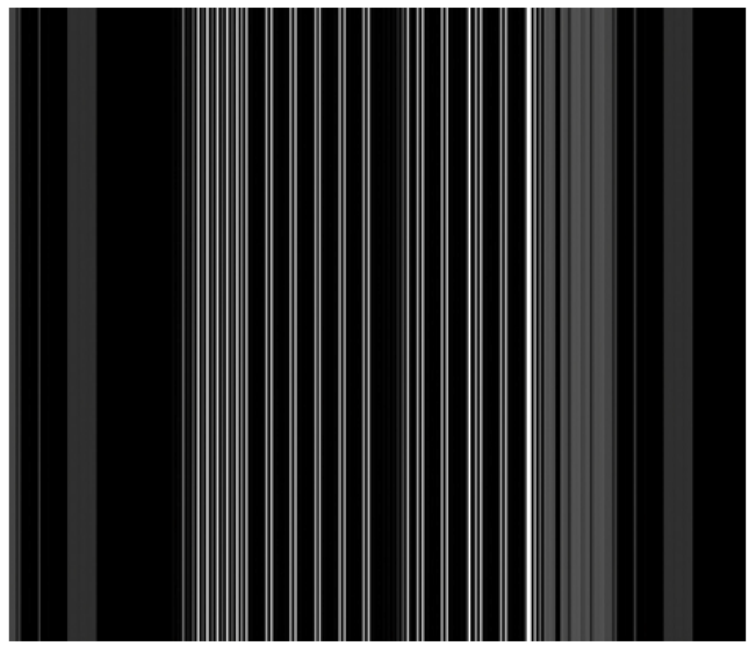

Fig. (9). Horizontal stress distribution in a clay layer deposited on a rock slope.

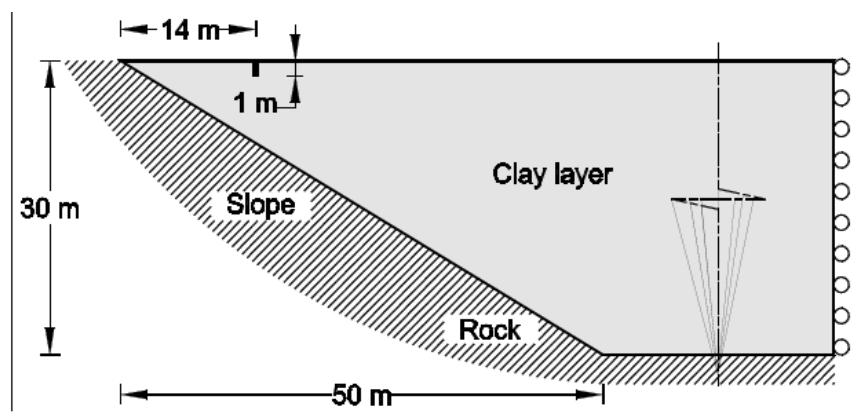

Fig. (10). Cracked clay layer deposited on a rock slope.

The normalized stress intensity factors calculated with this model are shown in Fig. (11). Under these conditions, the crack reaches a depth of $6.85 \mathrm{~m}$, and in its upper part an aperture, $b=27 \mathrm{~cm}$ (Fig. 12).

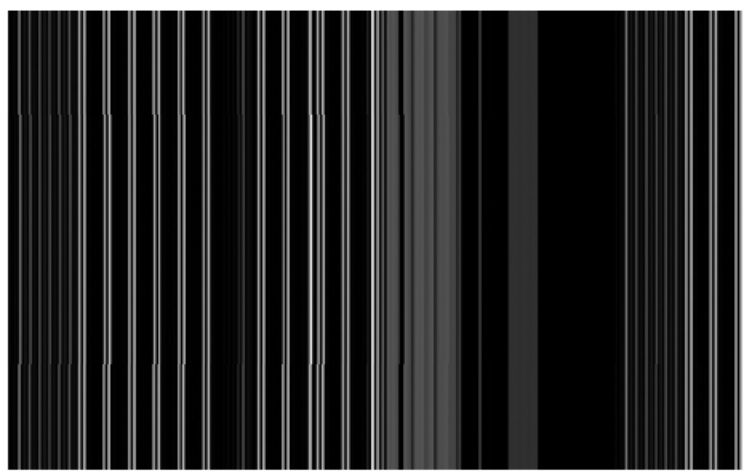

Fig. (11). Variation of $K_{I} / K_{I C}$ with crack-depth for a cracked clay layer deposited on a rock slope.

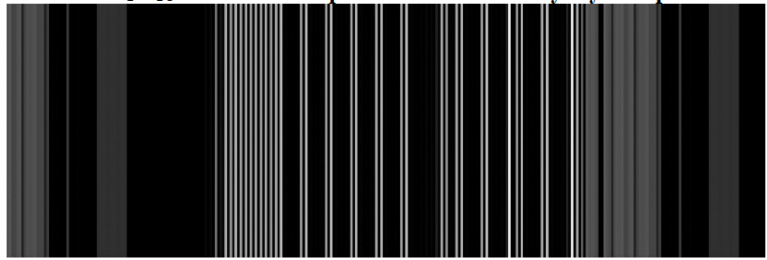

Fig. (12). Simulation of the crack growth in FRANC2D of a cracked clay layer de-posited on a rock slope.

\section{Case 3: Clay Layer Deposited on a Step}

To validate the statement of [13], that the occurrence of cracks is favorable in soil layers deposited on rock steps, this example studies a clay layer deposited on a $10 \mathrm{~m}$ high rock step (Fig. 13).

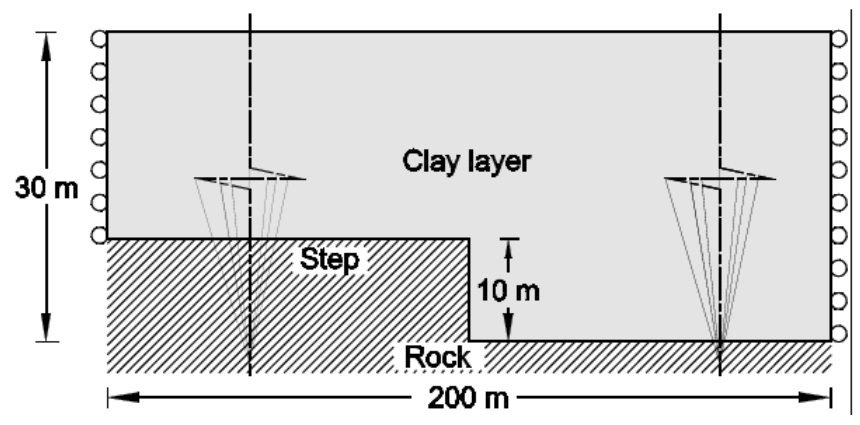

Fig. (13). Geometry of a clay layer placed upon a step irregularity.

The distribution of horizontal stresses obtained from the analysis is shown in Fig. (14). A tensile stressed region potential to the appearance of cracks, occurs near the surface above the side of the step. This region reaches a depth of $4.08 \mathrm{~m}$, with the maximum tensile stress located $7.5 \mathrm{~m}$ to the left of the jump defining the step.

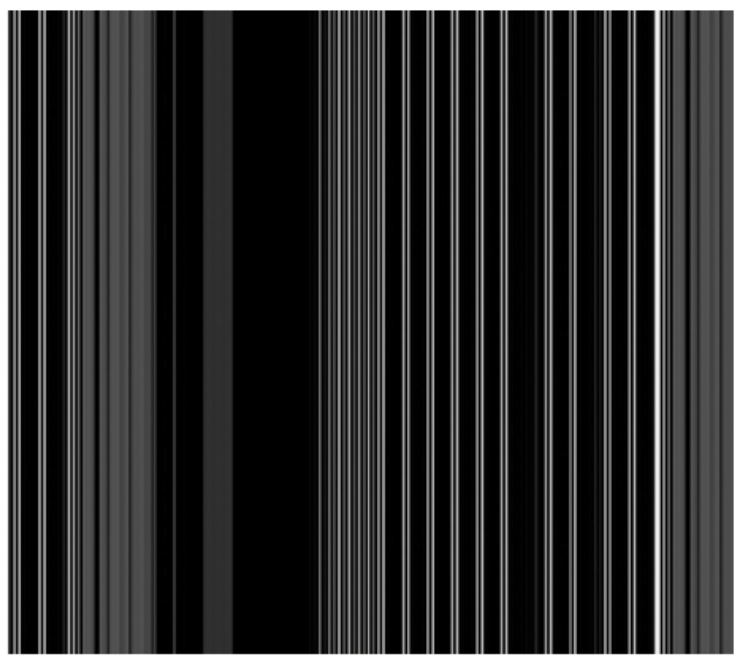

Fig. (14). Horizontal stress distribution of a clay layer deposited on a step.

Introducing an initial crack $1 \mathrm{~m}$ long (Fig. 15), the normalized stress intensity factors are shown in Fig. (16). In this case, the crack reaches a depth of $4.5 \mathrm{~m}$ and an aperture in its upper part of $b=27 \mathrm{~cm}$ (Fig. 17). 


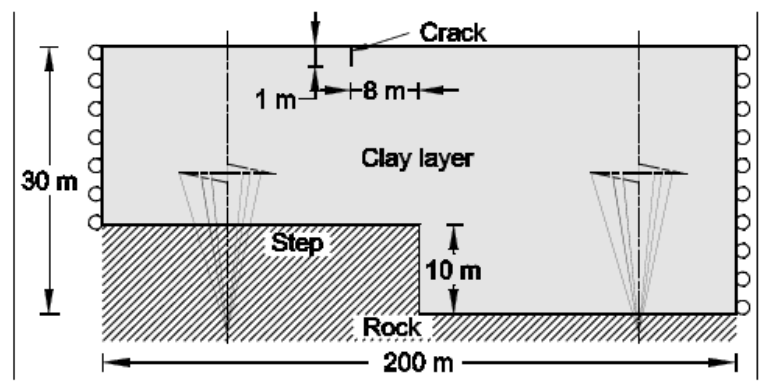

Fig. (15). Cracked clay layer deposited on a step.

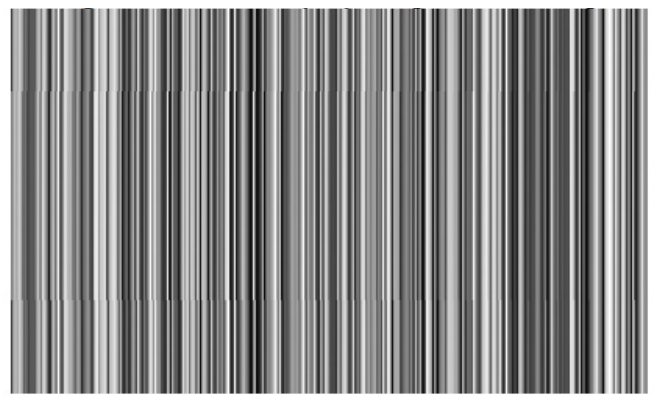

Fig. (16). Variation of $K_{I} / K_{I C}$ with crack-depth of a cracked clay layer deposited on a step.

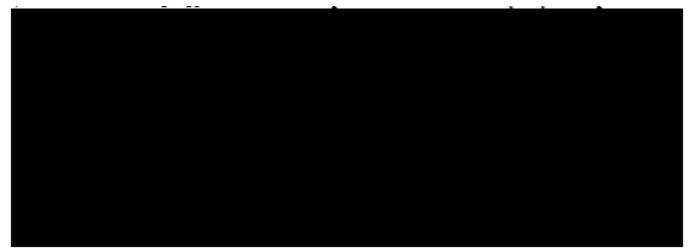

Fig. (17). FRANC2D simulation of the crack growth in a clay layer deposited on a step.

\section{Case 4: Soil Cracking Due to Water Pressure}

The filling of a crack with water induces normal stresses to its borders. This effect modifies the initial stress state in the vicinity of the crack tip; therefore, the possibility of growth increases. This example studies a $30 \mathrm{~m}$ deep cracked clay layer, with a crack whose borders were subjected to hydrostatic pressure (Fig. 18). The considered initial cracks were 1 and $2 \mathrm{~m}$ in lengths (Fig. 19). The stress intensity factors obtained in the analyses are shown in Table 1. In this Table, it is observed that, values of $K_{I}$ for both initial crack lengths are smaller than the critical value of $K_{I C}=12.7$ $\mathrm{kPa} \sqrt{\mathrm{m}}$. Consequently, there is no crack propagation under these conditions.

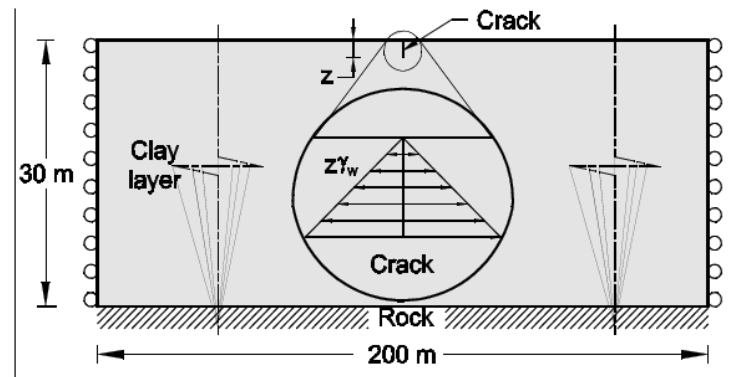

Fig. (18). Geometry of a cracked clay layer subjected to hydrostatic pressure.

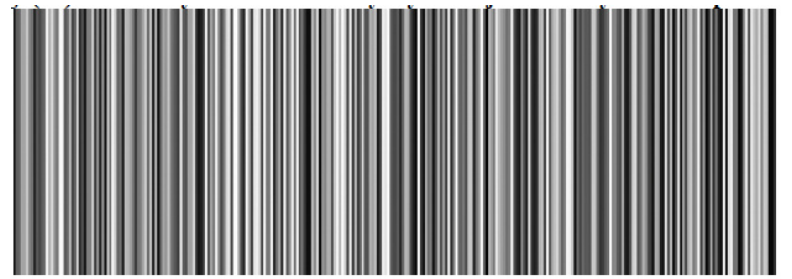

Fig. (19). Mesh used in FRANC2D of a cracked clay layer subjected to hydrostatic stress.

Table 1. Variation of $K_{I}$ Versus Crack Depth of a Cracked Clay Layer Subjected to Hydrostatic Pressure

\begin{tabular}{|c|c|}
\hline Depth $\mathbf{z}(\mathbf{m})$ & $\boldsymbol{K}_{\boldsymbol{I}}(\mathbf{k P a} \sqrt{\mathbf{m})}$ \\
\hline \hline 1 & 5.57 \\
\hline 2 & 10.86 \\
\hline
\end{tabular}

\section{Case 5: Cracking in Soils Due to Infiltration}

When a transient or permanent flow in a homogeneous mass of saturated soil is present, filtration forces per unit volume are generated denoted as $\vec{F}$. These forces are defined as

$$
\vec{F}=-\gamma_{w} \operatorname{grad} \phi
$$

It may be shown that during the processes of evaporation the water flow in a layer of soil is one-dimensional and transient [2], and that the hydraulic potential is defined by the equation

$$
\phi=\frac{I_{e}}{k} \gamma_{w}\left[z \operatorname{Erfc} \frac{z}{2 \sqrt{C_{v} t}}-2 \sqrt{\frac{C_{v} t}{\pi}} e^{\left(-\frac{z^{2}}{4 C_{v^{t}}}\right)}\right]
$$

where

Erfc $=$ complementary error function, defined as:

$$
\operatorname{Erfc}(x)=\frac{2}{\sqrt{\pi}} \int_{x}^{\infty} e^{-t^{2}} d t
$$

Substituting Eq. (2) into (1), the body force vector per unit volume produced by filtration in the soil structure is

$$
\vec{F}=-\frac{I_{e}}{k} \gamma_{w}^{2} \operatorname{Erfc} \frac{z}{2 \sqrt{C_{v} t}}
$$

Finally, the vertical direction body force per unit volume due to evaporation and subsequent infiltration and the action of the $\gamma_{A}$, is given by:

$$
\vec{Z}=\gamma_{A}-\frac{I_{e}}{k} \gamma_{w}^{2} \operatorname{Erfc} \frac{z}{2 \sqrt{C_{v} t}}
$$

Fig. (20) shows the variation with depth of the body force for different evaporation intensities and the properties of the clays in the Valley of Mexico, i.e., $k=5.45 \times 10^{-9} \mathrm{~m} / \mathrm{s}, C_{v}=$ $9.51 \times 10^{-8} \mathrm{~m}^{2} / \mathrm{s}, t=0.5, \gamma_{\mathrm{w}}=9.8 \mathrm{kN} / \mathrm{m}^{3}$; and $I_{e}=0.5,1.0$ and 
$1.5 \mathrm{~m} / \mathrm{y}$. In this figure, it may be observed that the value of the $\vec{Z}$, decreases with depth, and evaporation and subsequent infiltration processes have no effect at depths greater than $5 \mathrm{~m}$; likewise, as the evaporation intensity increases, $\vec{Z}$ increases in a non-linear way. The stress analyses of the model (Fig. 21) gave the variation of the stress state with the intensity of evaporation considering the action of $\vec{Z}$.

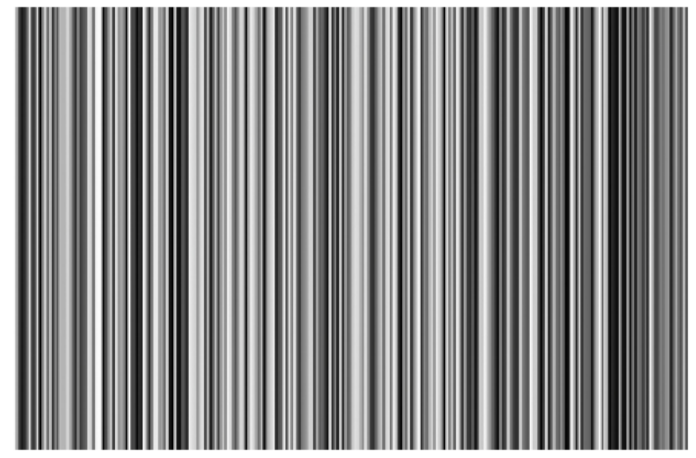

Fig. (20). Total body force Z.

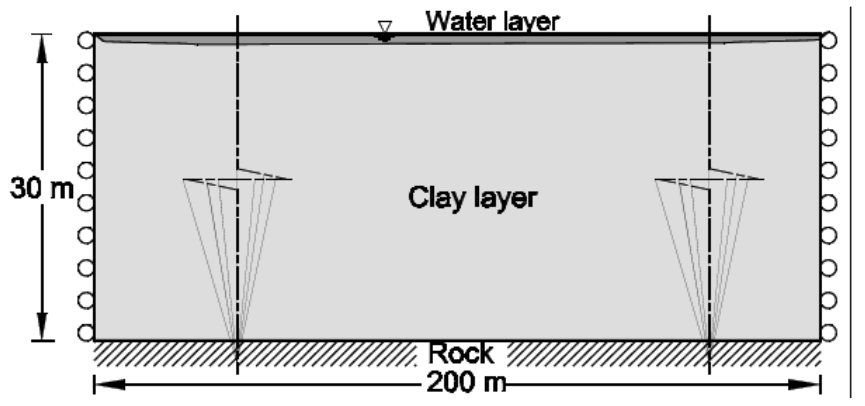

Fig. (21). Geometry of a clay layer exposed to evaporation and subsequent infiltration.

Fig. (22) shows the stress distributions in a clay layer exposed to evaporation and subsequent infiltration. It may be observed that the tension stress distribution reaches depths of $3.35,6.87$ and $10.30 \mathrm{~m}$ for $\mathrm{I}_{\mathrm{e}}=0.5,1.0$ and $1.5 \mathrm{~m} / \mathrm{y}$ respectively.

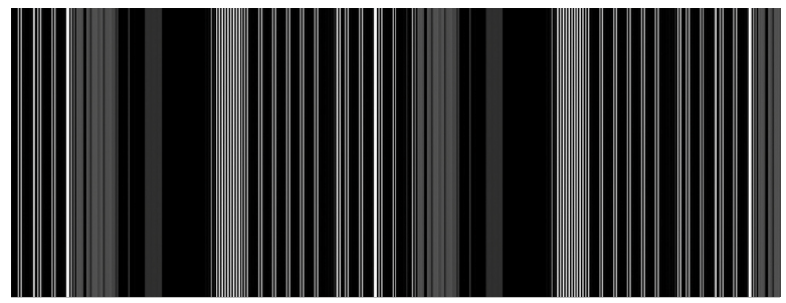

Fig. (22). Distribution of stresses in the clay layer exposed to evaporation and subsequent infiltration: a) vertical and b) horizontal.

For the simulation of the crack propagation, an initial crack $2 \mathrm{~m}$ long was introduced at the upper center of the model (Fig. 23), producing the normalized stress intensity factors shown in Fig. (24). The crack depths and the apertures b in the upper part (Fig. 25) are shown in Table 2.

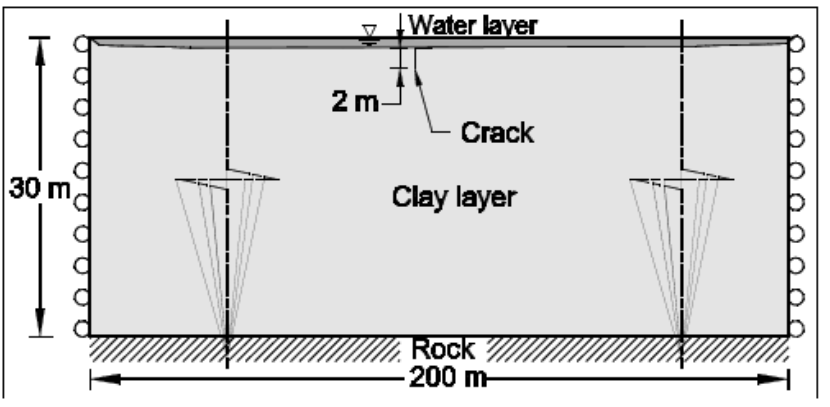

Fig. (23). Geometry of a cracked clay layer exposed to evaporation and subsequent infiltration.

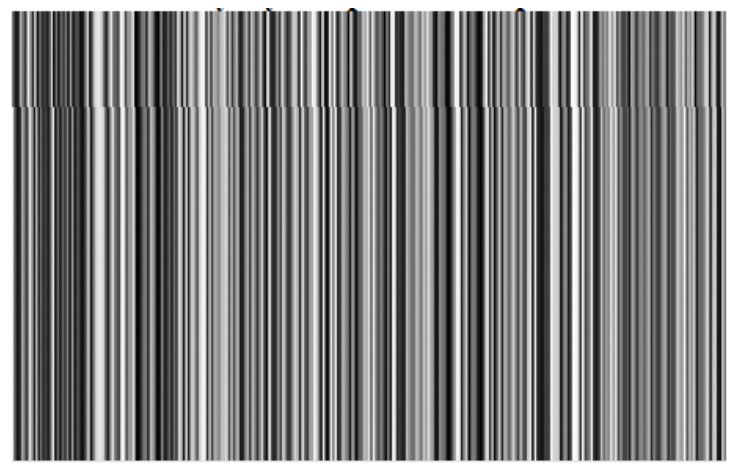

Fig. (24). Variation of $K_{I} / K_{I C}$ with crack-depth for a cracked clay layer exposed to evaporation and subsequent infiltration.

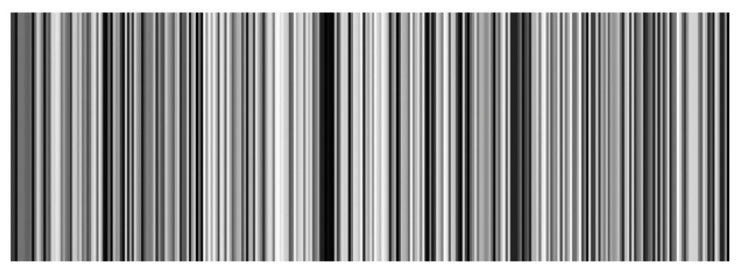

Fig. (25). FRANC 2D modeling of a cracked clay layer exposed to evaporation and subsequent infiltration.

Table 2. Depth and Displacements, b, at the Upper Part of the Crack Located in a Soil Subjected to Evaporation and Subsequent Infiltration

\begin{tabular}{|c|c|c|}
\hline $\mathbf{I e}(\mathbf{m} / \mathbf{y})$ & Depth $\mathbf{z}(\mathbf{m})$ & Displacement b $(\mathbf{m})$ \\
\hline \hline 0.5 & - & - \\
\hline 1.0 & 6.50 & 5.70 \\
\hline 1.5 & 13.10 & 18.22 \\
\hline
\end{tabular}

The above results show that, for evaporation intensities greater than $I_{e}=0.5 \mathrm{~m} / \mathrm{y}$, the growth of an initial crack in a clay layer is possible. In Fig. (22), it is observed that, the tensile stress distribution reaches depths of 6.87 and $10.30 \mathrm{~m}$ for $I_{e}=1.0$ and $1.5 \mathrm{~m} / \mathrm{y}$, respectively. However, the results presented in Table 2 show that the cracks reach depths of 6.5 and $13.1 \mathrm{~m}$, respectively. These results confirm that, as a crack propagates the stress state changes, and therefore analyses in which the propagation of cracks is ignored, are not representative of real situations. 


\section{Case 6: Cracking Due to Formation of a Puddle}

In order to check whether a crack will grow when a puddle is formed on the surface of a clay layer; a stress analysis of the model shown in Fig. (26) was carried out. In this case, in the soil region located under the puddle, body forces by unit volume are generated due to evaporation and subsequent infiltration processes, thus Eq. (5) is utilized to calculate these forces.

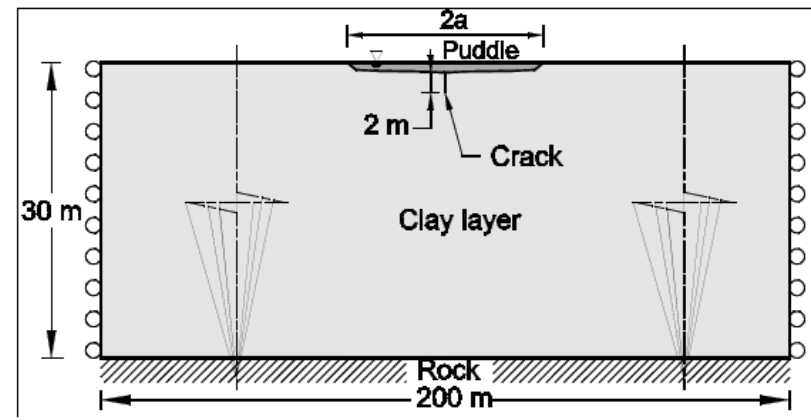

Fig. (26). Geometrical model of a cracked clay layer due to the formation of a puddle.

For the simulation of the crack propagation, an initial crack of $2 \mathrm{~m}$ long is inserted in the center region of a puddle of varying width $\mathrm{a}=5,10$ and $15 \mathrm{~m}$ (Fig. 26), with the same properties used in case 5 .

The normalized stress intensity factors calculated during the incremental analysis of the crack-growth are shown in Fig. (27). The crack depths and displacements $b$ in the upper part are shown in (Table 3 ).

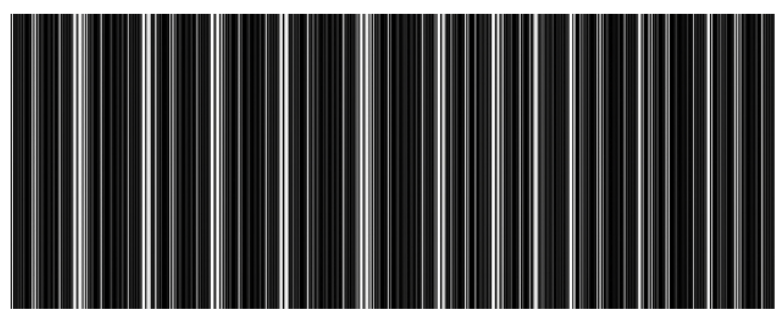

Fig. (27). Variation of $K_{I} / K_{I C}$ with crack-depth of a cracked clay layer exposed to evaporation and subsequent infiltration due to the formation of a puddle: a) $I_{e}=1 \mathrm{~m} / \mathrm{y}$ and b) $I_{e}=1.5 \mathrm{~m} / \mathrm{y}$.

\section{CONCLUSIONS}

From the numerical results obtained in the six cases studied in this paper, it can be concluded that:
1. In the first case studied, the appearance of cracks at the surface is related to the topography of the bearing layer, confirming the statement in [1], that the cracking phenomenon in soils is favorable in a soil layer deposited on a cylindrical rock base, which induces a tensile stress region into the soil placed on the rock. This tensile stress region also grows as the crack propagates.

2. In the second case studied, the appearance of cracks is a consequence of the pulling of the material of the clay layer deposited on the sloping rock. As a result, a tensile stress region is generated, and therefore, cracking is developed. This situation is not likely to occur if sliding of the clipping layer is possible. In this case, also the modification of the stress state can be seen as the crack propagates, because the reached crack depth, $6.85 \mathrm{~m}$, was bigger than the depth of original tensile stress region, 6.70 $\mathrm{m}$.

3. In the third case studied, cracking is caused by the region of larger thickness of the clay layer pulling the region deposited on the step. As a result, a tensile stress region is generated in the upper part of the layer; consequently, cracking is developed. Again, it is observed that the appearance of cracks on the surface is related to the topography of the bearing layer.

4. In the fourth case studied, the effect of a crack subjected to hydrostatic pressure produces a small increase in the stress intensity factor, which may not cause crack growth. Then, there is no problem for preexisting cracks when they are filled with water, modifying the stress state at the crack tip.

5. In the fifth case studied, it is observed that the evaporation and infiltration phenomenon produces crack growth when the evaporation intensities are greater than $I_{e}=0.5$ $\mathrm{m} / \mathrm{y}$. Furthermore, it is found that the crack depth is directly proportional to the evaporation intensity, $\mathrm{I}_{e}$, and inversely proportional to the coefficient of permeability, $\mathrm{k}$.

6. In the last case studied, it is observed that the maximum values of stress intensity factors correspond to the puddle of smaller width. However, when the crack depth increases, this relationship is inverted. This effect does not occur in the previous case where it is considered that the puddle covers the whole length of the layer. Hence, the crack depth depends on the evaporation intensity value and on the width of the puddle.

7. Authors as [10] have stated that cracks reach the depth of the tensile region obtained from the preliminary analysis

Table 3. Depth and Displacement, b, in the Upper Part of a Cracked Clay Layer Exposed to Evaporation and Subsequent Infiltration Due to the Formation of a Puddle

\begin{tabular}{|c|c|c|c|c|c|c|}
\hline \multirow{2}{*}{$\mathbf{I}_{\mathbf{e}}(\mathbf{m} / \mathbf{y})$} & \multicolumn{3}{|c|}{ Depth (m) } & \multicolumn{3}{c|}{ Displacement b (cm) } \\
\cline { 2 - 7 } & $\mathbf{a}=\mathbf{5} \mathbf{~ m}$ & $\mathbf{a}=\mathbf{1 0} \mathbf{~ m}$ & $\mathbf{a}=\mathbf{1 5} \mathbf{~ m}$ & $\mathbf{a}=\mathbf{5} \mathbf{~ m}$ & $\mathbf{a}=\mathbf{1 0} \mathbf{~ m}$ & $\mathbf{a}=\mathbf{1 5} \mathbf{~ m}$ \\
\hline \hline 0.5 & - & - & - & - & 11.90 & - \\
\hline 1.0 & 4.90 & 6.10 & 6.4 & 11.00 & 22.40 & 18.30 \\
\hline 1.5 & 6.20 & 8.20 & 9.60 & 19.10 & 20 \\
\hline
\end{tabular}


of a non-cracked soil system. However, in the cases investigated here, it is observed that the depths defined from the stress distribution of tensile stress are different from those reached by the crack defined using LEFM, and therefore results based only on tensile stress distribution are not correct.

\section{CONFLICT OF INTEREST}

The author(s) confirm that this article content has no conflicts of interest.

\section{ACKNOWLEDGEMENT}

The first author acknowledges the financial support by CONACYT under the agreement number I010/176/2012 with the Universidad Autónoma Metropolitana, in the context of the research project: "Analysis and design of concrete slabs". The second author acknowledges the support given by the General Directorate of Academic Personnel affairs of the Universidad Nacional Autónoma de México of the PAPIIT project IN108512.

\section{LIST OF ABBREVIATIONS}

$C_{v}=$ coefficient of consolidation

$C T O D=$ crack tip opening displacement

$E=$ modulus of elasticity

$G=$ energy release rate

$I_{e}=$ evaporation intensity

$J=$ integral $\mathrm{J}$

$k=$ coefficient of permeability

$K=$ stress intensity factor

$K_{I}=$ stress intensity factor in mode I

$K_{I C}=$ critical stress intensity factor in mode I

$t=$ time

$z=$ depth

$\vec{Z}=$ body force

$\Phi=$ the hydraulic potential

$\gamma_{A}=$ unit weight of the clay $\gamma_{w}=$ unit weight of water

$n=$ Poisson's ratio

$\sigma_{Y S}=$ tensile yield strength

\section{REFERENCES}

[1] M.K. Larson, "Potential for Subsidence Fissuring in the Phoenix Arizona USA Area", in Proceedings of the Third International Symposium on Land Subsidence, Venice, Italy, 1984, pp. 291-299.

[2] E. Juárez, "Mecanismos de grietas de tensión en el Valle de México", Ph. D. Thesis, Universidad Nacional Autónoma de México, Mexico, 1961. (In Spanish)

[3] J.F. Poland, and G.H. Davis, "Land subsidence due to withdrawal of fluids", Reviews in Engineering Geology, vol. 2, pp. 187-270, 1969.

[4] H.H. Schumann, and J.F. Poland, "Land Subsidence, Earth fissures and Groundwater Withdrawal in South Central Arizona, USA", in Proceedings of the Tokyo Symposium IASH/AIHS- UNESCO, 1969, pp. 295-302.

[5] T.L. Holzer, "Ground Failure in Areas of Subsidence due to Ground Water Decline in the United States", in Proceedings of the Second International Conference on Soil Mechanics and Foundation Engineering, IAHS-AISH Publication, Anaheim, CA, 1976, pp. 423-433.

[6] A.W. Bishop, "Progressive Failure With Special Reference to the Mechanism Causing It", in Proceedings of the Geotechnical Conference, Oslo, Norway, 1967, pp. 142-150.

[7] A.W. Skempton, R.L. Schuster, and D.J. Petley, "Joints and fissures in the london clay at Wraysbury and Edgeware", Geotechnique, vol. 19, pp. 205-217, 1969.

[8] L.E. Vallejo, "Fissure Interaction and the Progressive Failure of Slopes", in Proceedings of the Eleventh International Conference on Soil Mechanics and Foundation Engineering, San Francisco, CA, USA, 1985, pp. 2353-2356.

[9] G. Auvinet and A. Arias, "Propagación de Grietas", En: Agrietamiento en Suelos. Sociedad Mexicana de Mecánica de Suelos, México, pp. 21-31, 1991. (In Spanish)

[10] J. Alberro, and R. Hernández, "Fuerzas de Filtración y Fracturamiento Hidráulico", Instituto de Ingeniería, Report no 528, Universidad Nacional Autónoma de México, México, 1990. (In Spanish)

[11] FRANC2D, "Fracture Analysis Code for Two-Dimensional Problems, version 3.2 (2010)", Cornell Fracture Group, Cornell University, USA.

[12] D. Swenson, and A.R. Ingraffea, "A Finite Element Model of Dynamic Crack Propagation With an Application to Intersecting Cracks", in Proceedings of the Fourth International Conference on Numerical Methods in Fracture Mechanics, San Antonio, TX, 1987, pp. 191-204.

[13] G.E. Figueroa, "Mecanismos de Producción de Grietas Inducidos por la Explotación de Aguas”, Academia Mexicana de Ingeniería, Alternativas Tecnológicas, Mexico, vol. 29, pp. 3-9, 1989. (in Spanish) 